\title{
Comparison of a modified shell vial culture procedure with conventional mouse inoculation for rabies virus isolation
}

\author{
María de los Angeles Ribas Antúnez ${ }^{1 /+}$, Blanca Girón², Iraima Monsalvez², \\ Luis Morier', Gretel Acosta', Yahisel Tejero', Yanislet Cordero', Dainelyd Piedra' \\ ${ }^{1}$ Pedro Kouri Institute, Havana, Cuba ${ }^{2}$ Rafael Rangel National Institute of Hygiene, Caracas, Venezuela
}

\begin{abstract}
Rabies is a neurotropic disease that is often lethal. The early diagnosis of rabies infection is important and requires methods that allow for the isolation of the virus from animals and humans. The present study compared a modified shell vial (MSV) procedure using 24-well tissue culture plates with the mouse inoculation test (MIT), which is considered the gold standard for rabies virus isolation. Thirty brain samples (25 positive and 5 negative by the fluorescent antibody test) obtained from different animal species at the National Institute of Hygiene Rafael Rangel in Caracas, Venezuela, were studied by the MIT and MSV assays. Nine samples (36\%) were positive at $24 \mathrm{~h}$, $10(40 \%)$ were positive at $48 \mathrm{~h}$ and six (24\%) were positive at $72 \mathrm{~h}$ by the MSV assay. With the MIT assay, $76 \%$ were positive at six days post inoculation and $12 \%$ were positive at 12 and 18 days post inoculation. One sample that was negative according to the MSV assay was positive with MIT on the 12th day. The MSV procedure exhibited a sensitivity of $96.2 \%$, a specificity of $100 \%$, a positive predictive value of $100 \%$ and a negative predictive value $80 \%$. This procedure allowed for rapid rabies virus detection. MIT can be employed as an alternative method in laboratories without tissue culture facilities.
\end{abstract}

Key words: rabies - modified shell vial procedure - mouse inoculation

Rabies is an acute viral disease that causes encephalitis and is universally fatal. The rabies virus is distributed worldwide, such that this disease constitutes an important public health problem. Prevention and control programs that involve the mass vaccination of domestic animals and the development of diagnostic laboratory methods with high sensitivity and specificity have been organised (Rupprecht et al. 2006, Bruckner 2009).

The MIT is a technique used for rabies isolation and a large amount of virus can be isolated from a single mouse brain for strain identification purposes. This assay can be used in situations in which facilities for cell culture (CC) are not available. Once a validated and reliable $\mathrm{CC}$ unit is established in the laboratory, the mouse inoculation test (MIT) should be replaced with another assay to avoid the use of live animals. The CC method is less expensive and gives more rapid results (Favi et al. 1992, OIE 2011).

The shell vial procedure is a modification of the standard CC procedure and is useful for the rapid detection of virus in vitro. This assay has been employed for the isolation of different microorganisms. The original shell vial protocol has been adapted for use with 24-well tissue culture plates and centrifugation [modified shell vial (MSV)] and has been employed for the detection of dengue and other arboviruses (Caceda \&

+ Corresponding author: maribas@ipk.sld.cu

Received 15 May 2012

Accepted 18 October 2012
Kochel 2007). The purpose of this study was to replace the MIT with the MSV to reduce the time necessary for rabies virus isolation.

Thirty brain specimens ( 25 positive and 5 negative) from rabies cases analysed by fluorescent antibody test (FAT) were studied. The samples originated from different animal species ( $22 \mathrm{dogs}, 3$ bovines, 1 cat, 1 goat, 2 humans and 1 bat) and were obtained through the epidemiological surveillance program of the National Institute of Hygiene Rafael Rangel in Caracas, Venezuela, in 2008.

The rabies FAT was performed using the technique previously described by Bourhy et al. (1990) and the MIT was performed as reported by Koprowski (1996).

For the MSV assay, the cover slips and tubes that are traditionally employed in the shell vial procedure were substituted by plastic 24 -well plates. A $500 \mu \mathrm{L}$ suspension of N2A cells $(150-200,000$ cells $/ \mathrm{mL})$ was added to each plate and $200 \mu \mathrm{L}$ of the specimen supernatant (1:100 dilution) was used to inoculate the cell monolayers. The inoculated cells grown in the plastic 24-well plates were centrifuged for $1 \mathrm{~h}$ at $37^{\circ} \mathrm{C}$ and $3,000 \mathrm{rpm}$. The supernatant was discarded and $1 \mathrm{~mL}$ of Dulbecco's modified Eagle's medium containing 2\% foetal calf serum was added to each well. After $24 \mathrm{~h}, 48 \mathrm{~h}$ or $72 \mathrm{~h}$ at $37^{\circ} \mathrm{C}$ in $\mathrm{CO} 2$, inoculated cells were detached and fixed on immunofluorescent slides. Then, rabies virus antigen was detected by direct FAT.

Among the 30 samples previously analysed by FAT, 25 (96.2\%) specimens were confirmed to be positive for rabies by the MSV test and the MIT.

When the MSV assay and the MIT were compared, the MSV exhibited a $96.2 \%$ sensitivity ( $95 \%$ CI: $88.7-100)$, a specificity of $100 \%$, a positive predictive value of $100 \%$ 
and a negative predictive value of $80 \%$ (95\% CI: $45-100)$. The kappa value was 0.86 . A false-negative result was obtained by the MSV assay for one specimen that was positive by MIT on the 12th day post inoculation (Table I).

Several comparative studies of CC and the MIT have shown that CC is as sensitive as the MIT; however, other studies have found that $\mathrm{CC}$ is less sensitive than the MIT (Rudd \& Trimarchi 1987, Barrat et al. 1988).

In this study, the MSV assay was less sensitive, but more specific than the MIT and was also faster (positivity at $24 \mathrm{~h}$ post inoculation), more economical with respect to human resources and animals and inexpensive. In this assay, low-speed centrifugation is used to increase the rate of viral infection of susceptible cells. Low-speed centrifugation causes a low level of damage to the surface of the cells, thus increasing the rate of viral entry into the cells and decreasing the time necessary for infection (Jayakaerthi et al. 2006).

Table II summarises the distribution of results for rabies obtained using the MSV assay and the MIT at different times post inoculation. The mice were observed daily for 21 days and all dead mice were examined by FAT. Any deaths occurring during the first five days were regarded as non-specific due to stress, bacterial infection or other causes.

TABLE I

Comparison of the results of the modified shell vial (MSV) procedure and the mouse inoculation test

\begin{tabular}{lccc}
\hline MSV & Positive & Negative & Total \\
\hline Positive & 25 & 0 & 25 \\
Negative & 1 & 4 & 5 \\
\hline Total & 26 & 4 & 30 \\
\hline
\end{tabular}

negative predictive value: $80 \%$; positive predictive value: 100\%; sensitivity: $96.2 \%$; specificity: $100 \%$.

\section{TABLE II}

Distribution of the results for rabies detection using the modified shell vial (MSV) technique and the mouse inoculation test (MIT) (days/h post inoculation)

\begin{tabular}{lclc}
\hline \multicolumn{2}{c}{ MSV } & \multicolumn{2}{c}{ MIT } \\
\hline $\mathrm{h}$ & $\mathrm{n}(\%)$ & Days & $\mathrm{n}(\%)$ \\
24 & $9(36)$ & 6 & $19(73)$ \\
48 & $10(40)$ & 12 & $4(15.4)$ \\
72 & $6(24)$ & 18 & $3(11.5)$ \\
- & $-(-)$ & 21 & $0(0)$ \\
\hline & $25^{a}(100)$ & & $26(100)$ \\
\hline
\end{tabular}

$a$ : one sample that was negative according to the MSV was positive by the MIT on the 12 th day.
On days 6, 12 and 18 post inoculation, one mouse from each sample was analysed by FAT (Favi et al. 1992).

The MSV assay had a positivity of $36 \%$ at $24 \mathrm{~h}$ post inoculation, $40 \%$ at $48 \mathrm{~h}$ and $24 \%$ at $72 \mathrm{~h}$. For the MIT, $73 \%$ positivity was obtained at six days after inoculation and a positivity of $11.5 \%$ was observed at $12(15.4 \%)$ and 18 days. Approximately one-third of the samples assessed using the MSV assay were positive between 24-48 h post inoculation. The average MIT incubation period was five days (range 8-28 days).

According to the 1984 guidelines of the World Health Organization Experts Committee, mice should be sacrificed after the fourth day post inoculation because the symptoms observed during the first 24-48 h could be attributed to other causes, such as trauma, poor inoculation technique and bacterial contamination (Bourhy et al. 1990).

When the treatment of a patient exposed to rabies is necessary, it is not practical to wait for the MIT results. Delays in diagnosis increase the number of persons potentially exposed to the rabies virus; moreover, early diagnosis can reduce the cost of treatment by eliminating unnecessary vaccination and allow for the implementation of potentially useful emerging therapeutic strategies.

This report is believed to be the first study on rabies virus isolation using a modified shell vial technique. This assay can make a major contribution to rabies diagnosis and the MIT can be used when ambiguous or negative results are obtained by FAT and cell culture.

\section{REFERENCES}

Barrat J, Barrat M, Picard M, Aubert M 1988. Diagnosis of rabies infection by cell culture. Comp Immunol Microbiol Infect Dis 11: 207-214.

Bourhy H, Sureau P, Tordo N 1990. Selection by direct immunofluorescence technique on fresh specimens. In H Bourhy, P Sureau, Laboratory methods for rabies diagnosis, Unite de la Rage, Paris, p. 169-170.

Bruckner G 2009. Rabies - The role of the World Organization for animal health in mobilising global control. Vaccine 27: 7139-7140.

Caceda ER, Kochel TJ 2007. Application of modified shell vial culture procedure for arbovirus detection. PLOS ONE 2: e1034.

Favi M, Roos O, Yung V 1992. Evaluación de la técnica de cultivos celulares frente a la inoculación en ratones lactantes en el diagnóstico de rabia. Av cienc vet 7: 172-179.

Jayakaerthi R, Potula R, Srinivasan S, Badrimath S 2006. Shell vial culture assay for the rapid diagnosis of Japanese encephalitis, West Nile and dengue 2 viral encephalitis. Virol J 3: 1-7.

Koprowski H 1996. The mouse inoculation test. In F Meslin, M Kaplan, Koprowski H, Laboratory techniques in rabies, World Health Organization, Geneva, p. 80-87.

OIE - Organization for Animal Health 2011. Manual for diagnostic test and vaccines for terrestrial animals. Available from: oie.int/ eng/normes/mmanual/A_summry.htm.

Rudd R, Trimarchi C 1987. Comparison of sensitivity BHK21 and murine neuroblastoma cells in the isolation of the street strain rabies virus. J Clin Microbiol 25: 1456-1458.

Rupprecht C, Hanlon C, Slate D 2006. Control and prevention of rabies in animals: paradigm shifts. Dev Biol 125: 103-111. 